\title{
Mapping the use of simulation in prehospital care - a literature review
}

Anna Abelsson ${ }^{1 *}$, Ingrid Rystedt', Björn-Ove Suserud ${ }^{2}$ and Lillemor Lindwall ${ }^{1}$

\begin{abstract}
Background: High energy trauma is rare and, as a result, training of prehospital care providers often takes place during the real situation, with the patient as the object for the learning process. Such training could instead be carried out in the context of simulation, out of danger for both patients and personnel. The aim of this study was to provide an overview of the development and foci of research on simulation in prehospital care practice.

Methods: An integrative literature review were used. Articles based on quantitative as well as qualitative research methods were included, resulting in a comprehensive overview of existing published research. For published articles to be included in the review, the focus of the article had to be prehospital care providers, in prehospital settings. Furthermore, included articles must target interventions that were carried out in a simulation context.

Results: The volume of published research is distributed between 1984- 2012 and across the regions North America, Europe, Oceania, Asia and Middle East. The simulation methods used were manikins, films, images or paper, live actors, animals and virtual reality. The staff categories focused upon were paramedics, emergency medical technicians (EMTs), medical doctors (MDs), nurse and fire fighters. The main topics of published research on simulation with prehospital care providers included: Intubation, Trauma care, Cardiac Pulmonary Resuscitation (CPR), Ventilation and Triage.

Conclusion: Simulation were described as a positive training and education method for prehospital medical staff. It provides opportunities to train assessment, treatment and implementation of procedures and devices under realistic conditions. It is crucial that the staff are familiar with and trained on the identified topics, i.e., intubation, trauma care, $\mathrm{CPR}$, ventilation and triage, which all, to a very large degree, constitute prehospital care. Simulation plays an integral role in this. The current state of prehospital care, which this review reveals, includes inadequate skills of prehospital staff regarding ventilation and CPR, on both children and adults, the lack of skills in paediatric resuscitation and the lack of knowledge in assessing and managing burns victims. These circumstances suggest critical areas for further training and research, at both local and global levels.
\end{abstract}

Keywords: Simulation, Prehospital, Systematic literature review

\section{Introduction}

Across the globe, prehospital settings are frequently associated with premature death [1]. With more rapid and more correct care efforts, some deaths due to high energy trauma could potentially be prevented [2]. However, training on accident scenes are hard to create, given that high energy trauma is rare. It is frequently also unsafe to use such unstable patients as training objects. Therefore, it is valuable to create real-life training opportunities in artificial contexts [3-5]. Simulation

\footnotetext{
* Correspondence: anna.abelsson@kau.se

'Department of Health Sciences, Karlstad University, Karlstad, Sweden

Full list of author information is available at the end of the article
}

facilitates both the initial learning and repeated rehearsals of specific management of critical incidences [6]. It provides for training under optimal conditions [4], of importance in e.g. high-stake scenarios [7]. Regularly scheduled prehospital training opportunities would enable staff to be better prepared and more confident at trauma scenes.

Consequently, simulation plays an increasing role in prehospital care management training [6,8]. Therefore, research into its effectiveness and comparisons of instructional designs are increasingly important [4]. Research on simulation as a learning tool for prehospital care providers is still limited [3]. The field is a relatively young and still relatively unsystematised although some reviews have 
been published $[4,9,10]$. However, a more complete accounting of all existing studies is still lacking [9].

Consequently, the goal of this review is to create a map of the existing field of research on simulation in prehospital care settings. The overview can serve as a base for future research on methods, effectiveness, efficacy and/or technical skills.

The review documents historical developments, including developments in geographical regions. It is important to note that the presence of research on simulation in one region does not imply that prehospital care in this region necessarily is of better quality. However, in order to continue to develop learning opportunities and continual education, each region will likely benefit from research conducted in settings with reasonably similar culture, context, conditions and resources, as their own. Further, the review documents what methods were targeted in the simulation exercises and for whom, i.e., what professional categories were the foci of the simulation exercises, as research participants. Hopefully, this overview of research may suggest knowledge gaps and important next steps regarding simulation in the prehospital care settings. Furthermore, it may act as stimuli for research on simulation in prehospital contexts, across geographical areas and with methodologies which have not yet been prioritized.

The aim of this study was to provide an overview of the development and foci of research on simulation in prehospital care practice.

\section{Methods}

An integrative literature review was carried out [11-13]. The integrative method allowed for the inclusion of studies from several different research methods. It plays a significant role in evidence-based practice as a more comprehensive understanding of specific problems within healthcare is formed [13].

\section{Search strategies}

Electronic searches were conducted in the databases Cinahl, Pubmed and Scopus during the month of February, 2013. The searches were carefully documented [13]. Search terms which were used included: emergency medical technicians, paramedic, manikin, simulation, ambulance and prehospital. Peer reviewed journals were included in Cinahl, in order to get the same results in Scopus, the search was limited to articles. Further combinations of search terms were carried out with the words: emergency, trauma, model, anatomic, training and education. These new combinations, however, generated no new references. The search utilized the Internet as well as reference lists of existing articles.

\section{Selection}

The inclusion criteria were articles published as primary research, quantitative as well as qualitative studies. Furthermore, the research participants in included articles should be prehospital care providers, including paramedics, EMTs, MDs, nurses and fire fighters performing or participating in some kind of simulation. The simulation should have been performed in a prehospital context. Finally, the articles should have been peer-reviewed and published before January $1^{\text {st }}, 2013$. If non-English articles were to be included, an abstract in English was required.

The electronic search, inspired by Jadad et al [14] and Oxman [15], generated 865 hits, of which 147 were duplicates, resulting in 718 articles to review. Two persons then independently read titles and abstracts in order to identify studies that matched the aim and the inclusion criteria of the review. A total of 243 relevant articles were downloaded or ordered as full-text versions. The 243 retrieved articles were subsequently read in full by one reviewer (AA) to confirm the relevance to the purpose of the review and to ensure that the inclusion criteria were met. Consequently, out of the 243 articles, 165 were included in the study. Of these 165 articles originated 111 from Cinahl, published between 1989 and 2012. Forty articles of the 165 articles were located in PubMed, published between 1989 and 2012. Finally, 14 articles of the 165 articles were identified in Scopus, published between 1984 and 2012 (Table 1).

Three additional reviewers (IR, BOS and LL) read and assessed samples of the 165 articles, in order to confirm that they made the same conclusions regarding inclusion into the review. This contributed to making the selection process transparent and thorough, as suggested by Oxman [15]. The reviewers reached a high level of agreement in the assessment process and any differences were discussed and agreement reached. Jadad et al [14] argue that it is ideal that all relevant literature on the subject is included in a review. Given that the purpose of the review was to provide an overview of research, it was therefore decided to include all 165 studies in the results.

Table 1 The selection process

\begin{tabular}{llll}
\hline Database & Number of hits & $\begin{array}{l}\text { Full article retrieved } \\
\text { and reviewed }\end{array}$ & Included \\
\hline Cinahl & 639 & 176 & 111 \\
Pubmed & $104\left(49^{*}\right)=55$ & 51 & 40 \\
$\begin{array}{l}\text { Scopus } \\
\begin{array}{l}\text { Total number } \\
\text { of studies }\end{array}\end{array}$ & $122\left(98^{*}\right)=24$ & 16 & 14 \\
\hline
\end{tabular}

*Duplicates. 


\section{Data analysis}

A systematic data analysis was conducted in accordance with Whittermore and Knafl [13]. The material was grouped in accordance to findings that answered the aim and formed into groups: history, geography, staff and five topics of simulation research. Qualitative and quantitative findings complemented each other given that the research addressed different but yet connected questions. The approach also enabled us to combine data from different studies and a scope could be assembled to create an overview over existing research [11-13].

\section{Results}

The results illustrate how the volume of published research has been distributed through time as well as across regions. It similarly reveals what simulation methods and what staff categories are generally the focus of research. Finally, as a consequence of the aim of mapping the extent of existing studies, this review reflects details on the prehospital topics most extensively covered in the field: Intubation, Trauma care, CPR, Ventilation and Triage.

\section{History and geography}

The aim was to provide an overview of development and foci of research on simulation in prehospital practice. Only a limited number of countries, worldwide, have published research on simulation with prehospital medical staff. The number of published articles increased markedly around the year of 2000. In the review, 85 published articles originate from the US. At the turn of the millennium, similar research started to be carried out and published in UK and Canada, and a few years later in other countries. UK was the first European country to regularly publish research on simulation in the context of prehospital care, several years of Germany and Scandinavia, (Table 2).

Through 2010, 55\% of published articles have originated from North America. During the same time frame, European published articles represent $30 \%$ of the total, and approximately $5 \%$ have originated from Oceania and Asia. After 2010, in comparison to before 2010, the share of published articles on simulation in the prehospital context from Europe has increased, whereas the North American share has decreased.

\section{Simulation methods focused on}

The published research focused on a number of simulation methods. Simulation with manikins was the most common method studied across all regions (143 studies). Simulations with films, images or paper as tools were the focus on research in 14 of the published studies. In Asia; films, images and paper represented approximately $40 \%$ of their methods evaluated. Compared to only $5 \%$ of the published articles in North America. Live actors, as a simulation tool, were used in 12 studies (11 were from North America), whereas cadaver were used in 6 studies ( 5 from North America). Finally, virtual reality as the method of simulation of prehospital care situations was used in 3 studies (all from North America). Some studies integrated several simulation methods in the same published article and were included in all the different methods.

\section{Research participants in simulation exercises}

Overall, published research on simulation in the context of prehospital care $(n=165)$ was, in the review, conducted with the following professions as participants: paramedics $(\mathrm{n}=111,46 \%)$, EMTs $(\mathrm{n}=59,24 \%)$, MDs $(\mathrm{n}=34,14 \%)$, nurses $(n=31,13 \%)$ and fire-fighters $(n=7,3 \%)$. More than half of the research on simulation published across all regions focused on paramedics. During the past five years, research on simulation focusing on paramedics has increased while, concurrently, the share of published research articles focusing on EMTs has declined. The share of published studies focusing on MDs and on nurses remains stable.

\section{Topics focused on in simulation}

The specific foci of the simulation exercises which were reported on the published articles revolved around five areas of methods for and/or techniques for prehospital care: Intubation, Trauma care, CPR, Ventilation and Triage.

\section{Intubation}

Intubation was the primary focus of research on simulation (36\% of the articles). Research on simulation exercises focusing on intubation started in 1996, and intubation has since then continued to be a common focus of simulation research (Table 3).

Most of the published articles on simulation and intubation were carried out with paramedics (58\%) as

Table 2 Published articles distributed by year and continent

\begin{tabular}{|c|c|c|c|c|c|c|c|}
\hline & 1984-1988 & 1989-1993 & 1994-1998 & 1999-2003 & 2004-2008 & 2009-2013 & Total \\
\hline North America & 1 & 6 & 10 & 12 & 37 & 29 & 95 \\
\hline Europe & & 1 & 6 & 1 & 7 & 34 & 49 \\
\hline Oceania & & & & 1 & 4 & 5 & 10 \\
\hline Asia & & & & 2 & 1 & 4 & 7 \\
\hline Middle East & & & & 1 & & 3 & 4 \\
\hline
\end{tabular}


Table 3 Number of articles focusing on intubation, published by continent 1984-2012

\begin{tabular}{ll}
\hline North America & 38 \\
Europe & 15 \\
Oceania & 3 \\
Middle East & 2 \\
Asia & 1 \\
Total & 59 \\
\hline
\end{tabular}

research participants, only one article on intubation involved military staff. Among the published simulation studies which targeted intubation, comparisons of different laryngoscopes or tubes was the most common (70\%), including studies on different techniques for intubation/ Bougie assisted intubation/free airway [16-52].

The remaining articles (30\%) highlighted the positive effects on learning and improved skills as a consequence of intubation training [53-66]. Some articles described how the intubation was affected by positioning of staff and patient, as well as by external conditions [67-76].

\section{Trauma care}

Trauma care, including prehospital procedures, was the focus of $32 \%$ of published research on simulation exercises. Most research on simulation with trauma care as the specific focus has been published after 2000 (Table 4).

Research participants in simulations focusing on trauma care included paramedics ( $44 \%$ of all articles), EMT's (22\%) and MDs (20\%). Seven articles on simulation in the context of trauma care targeted military staff.

Simulation exercises focusing on trauma care basically concerned simulation training methodology and staff performance, which included paediatric resuscitation, intraosseous needle insertion and intranasal medication. They also targeted the assessment of, for example, burn victims, blood loss or immobilisation of the trauma patient. A smaller share described the prehospital work environment.

\section{Simulation as a method for education in trauma care}

Several of the studies focused on how fidelity as well as simulation method, in themselves, impacted the experience of the simulation exercise [77-91]. These articles highlighted that simulation provided a positive and helpful

Table 4 Number of articles focusing on trauma care, published by continent 1984-2012

\begin{tabular}{ll}
\hline North America & 33 \\
Europe & 12 \\
Oceania & 6 \\
Middle East & 2 \\
Asia & 0 \\
Total & 53 \\
\hline
\end{tabular}

opportunity to train under stress [92-95] and was an effective way to train for biological, chemical, nuclear and terror attack scenarios [96-100].

\section{Performance}

A research study focusing on paediatric resuscitation skills concluded that the performance of the paramedics were deficient in one way or another regarding infant cardiopulmonary arrest (55\% of the paramedics did not perform this correctly), infant respiratory arrest (48\%) and infant sepsis (53\%) [101] which suggest a need for continuous staff education in paediatric trauma care.

Three studies regarding intraosseous needle insertion supported that it was easy to learn for the prehospital provider with a satisfactory success rate and few complications [102-104] as was administering intranasal medication when performed by 18 advanced paramedic trainees in a randomised controlled trial [105]. This indicated that both intraosseous needle insertion and intranasal medication is something that could be used more frequently in the prehospital care. A similar circumstance was observed in the context of ultrasound were 2 studies showed that correct use of ultrasound was achieved by the prehospital staff after relatively little training $[106,107]$ which indicated that ultrasound could be used diagnostically in prehospital situations. Studies showed that certain types of performance could be improved with external help. If the staff had access to physicians via telemedicine a more advanced care could be ensured, including caring for major trauma and myocardial infarction successfully performing needle thoracostomy and pericardiocentesis [108,109].

Limitations occurred regarding staff's clothing where the study showed that working with protective clothing prolonged the prehospital care-taking process [110,111], as did working with night goggles in a randomized clinical trial when performed by 26 emergency physicians and paramedics [112]. At certain prehospital situations, the patient's clothing instead posed a limitation because of the risk of hyperthermia. Two studies focused on desired and un-desired cooling of the patient. One study showed that removing wet clothing and using windproof and compression resistant outer ensemble protected against cold $[113,114]$ while regularly changing cooled intravenous infusions resulted in desired patient hypothermia [115].

It also appeared that there were some limitation in staff's willingness to restrain an agitated or violent patient, even though the staff had training in restraining [116] as well as the functionality of various types of tourniquet when performed by 10 military EMTs [117].

\section{Assessment}

Ten articles focusing on simulation of trauma care scenarios aimed at assessment. Two articles emphasised that there was a lack of training on the management of burns 
victims [118,119]. One of this studies, performed with 198 participants, showed that prehospital staff frequently underestimated the total burned surface area burned of the burn victims. This resulted in only $13 \%$ of the calculations of resuscitation fluid being correct (118). The other was a comparative simulation study, which showed that 125 emergency service and military paramedic staff over or under estimated the burn area to approximately $50 \%$ of 10 burn victims (119). Both these results indicate that the survival outcome diminishes.

When it came to immobilisation of trauma patients, training and experience resulted in 10 paramedics and 10 MDs made the same assessment in a randomized, prospective study. This demonstrated that the paramedics were able to reliably evaluate patients for possible cervical spinal injury [120]. But regardless of training or experience, the assessment of the patient's loss of blood on the ground was in 3 studies regarded as too inaccurate to be of significance in the actual care [121-123], which point to the prehospital staff not taking time on the scene of the accident to assess blood losses.

\section{Work environment}

Two studies focused on work environment and showed that carrying stretchers and being exposed to prehospital working postures burdened the body [124-126], while vibrations in the cabin of a controlled ambulance transport could be reduced by using mattresses [127].

\section{Cardiac pulmonary resuscitation (CPR)}

CPR represented $20 \%$ of the published research on simulation. Seven articles were published on CPR between 1995 and 2005, and since then, 2-4 articles have been published on CPR annually, resulting in a total of 35 articles (Table 5). Research on CPR declined somewhat between the years 2008 and 2012.

The majority of the published articles, $43 \%$, focused on how EMT: s carried out CPR, whereas 33\% focused on paramedics and $8 \%$ on fire fighters. Only one article that focused on military staff was found.

Poor CPR implementation during simulation was identified in 8 studies [128-135]. According to 6 studies the participants performed inadequate compressions in $32 \%-62 \%$ of the times [129-135] and had misplaced hands in 36\% -

Table 5 Number of articles focusing on CPR, published by continent 1984-2012

\begin{tabular}{ll}
\hline North America & 11 \\
Europe & 19 \\
Oceania & 0 \\
Middle East & 0 \\
Asia & 5 \\
Total & 35 \\
\hline
\end{tabular}

$55 \%$ [129-131]. It was also found in two studies that 50\% $90 \%$ of ventilations during CPR were incorrectly performed $[129,130]$. The quality of CPR was relatively similar regardless of group of staff. Participants in 3 studies were not able to accomplish CPR that would likely have been of clinical benefit for an actual patient. The number of people performing CPR affected the implementation [136-138], as did the positioning of the staff [134,139-141]. CPR during simulation was also affected by external factors. CPR was described as possible to perform with adequate quality during surf lifesaving [142] but was negatively affected by such factors as car movement or carrying of stretcher $[133,135,143,144]$. The compression rate while performing CPR, varied also due to external factors such as audible feedback [131] which resulted in improved compression competence over time when training with a voice-assisted manikin [145]. External factors, such as dressing in protective clothing, prolonged the time taken for implementation of CPR [146,147] while the removal of a patient's clothes using a cutter affected positively as it was quicker than using scissors in a manikin study when performed by 10 persons [148].

Articles differed regarding the use of external mechanical compressions instead of compressions performed by the prehospital staff. Both positive and negative effects were identified [149-155]. Malposition of the mechanical compression device counteracted the benefit of mechanical chest compressions. Still, participants using the external mechanical compression device adhered more closely to CPR guidelines than participants using active compressiondecompression (ACD) CPR. ACD CPR caused a reduction of compression quality and many participants regarded ACD CPR difficult to use due to not being tall enough to apply the device [149-152]. Hands off time, i.e. time without compressions, was described as longer when using a mechanical device than manual compressions [153]. When using feedback devices regarding chest compressions these were described to overestimate the depth but withhold the compression efficacy $[154,155]$.

The use of automatic defibrillation was described as quicker than manual defibrillation in the field, in a randomized simulation study which included 74 military medical participants [156]. Furthermore, reduced hands-off time was the result of manual defibrillation [157]. Both high and low fidelity simulation of cardiac arrest resulted in satisfied participants [158].

\section{Ventilation}

Between the years 1989 and 1994, 6 articles were published on simulation in the context of ventilation, representing $6 \%$ of the total research articles. Following 1994, simulation regarding ventilation disappeared as an area of research and never quite returned. Only 5 articles focusing on simulation and ventilation were published in 
the years 2005-2011. Between 2008 and 2012 publications followed the same trend and stayed approximately the same as earlier, constituting $5 \%$ of the research with a total of 11 articles published (Table 6).

Research on simulation and ventilation has mainly been carried out with paramedics as the research participants, $50 \%$ of all articles focusing on ventilation and with EMTs, 29\%.

The articles focusing on ventilation emphasised that ventilation was difficult and often had an unsatisfying result. Accordingly to two studies, to improve the quality of ventilation during CPR, a higher number of staff involved in the patient care was needed [159]. In addition, the ventilation quality was improved when the ventilation was performed mouth-to-mouth. However given that prehospital care providers may consider mouth-to-mouth ventilation unacceptable for regular use, a pocket mask with oxygen inlet was suggested [160], even though ventilation using a pocket mask was described as difficult. Three studies showed that adequate ventilation with mouth to mask on children was performed in between only $40-75 \%$, depending on the type of pocket mask devices being used [161,162] and with $20 \%$ of excessive pressure breaths [163].

Also bag- valve- mask showed, in 3 studies, difficult for the participants to use. When conducting bagvalve- mask ventilation, 60 out of 70 participants did not achieve adequate tidal volume in a paediatric manikin. Bag- mask- ventilation was associated with a significant large percentage, 56\%, of excessive pressure breaths, $[160,163,164]$. One study showed that smaller 1-litre bags yielded better results than bigger 1,6 litre bags when performed by 30 paramedic students [165]. Also, a mechanical bag controller was shown to provide a small advantage compared to manual bag ventilation [166]. On the contrary, demand valve and automatic ventilators did not provide satisfactory ventilation on non-intubated patients in a comparison study performed by 15 EMTs [167].

Staff auscultation skills on intubated patients could be improved by training with simulated heart and lung sounds [168]. However, the only quick way of discovering a dislocated tube was to use capnography [169].

\begin{tabular}{lr}
$\begin{array}{l}\text { Table } \mathbf{6} \text { Number of articles focusing on ventilation, } \\
\text { published by continent } \mathbf{1 9 8 4 - 2 0 1 2}\end{array}$ \\
\hline North America & 7 \\
Europe & 2 \\
Oceania & 1 \\
Middle East & 0 \\
Asia & 1 \\
Total & 11 \\
\hline
\end{tabular}

\section{Triage}

Triage targeted $6 \%$ of the published research articles on simulation. A total of 10 articles on simulation and triage have been published since 2001; 6 in North America, 2 in Europe and Asia, respectively. The research underlying the articles focused on triage carried out with paramedics as research participants, $31 \%$, whereas $25 \%$, respectively, has been carried out with a focus on EMTs and MDs as research participants.

The articles focused on triage demonstrated that triage training improved the staff's knowledge [170-173] including virtual reality training performed by 182 nurses, physicians and paramedics [174]. Table top exercise when performed by 59 EMTs was not evaluated as ideal due to the lack of actual implementation with equipment [175]. But if floor top exercise were performed with addition film screening of previous disaster drills it was experienced to provide the participants with a clearer picture of the situation [176]. If live victims scenarios were used instead, the participants scored this higher than written scenarios without significant differences and were, by 61 prehospital providers in an exploratory study, compared favourably, to manikins. This suggests that the two methods, live victims and written scenarios, although different in regards to cost, time- and space consumption may result in similar learning outcomes [177].

Using decision-making material resulted, according to a comparison study including 93 emergency service personal, in a more correct and quicker assessment [178]. It also improved participant confidence in a prospect observational study conducted with 73 in- and prehospital participants [179]. This suggests that some sort of support material works favourable for prehospital triage decision-making.

\section{Discussion}

This study suggests there are relatively few published articles focusing on simulation in prehospital healthcare. The number of articles has increased in the last few years with a significant number of articles originating from North America. The research of a few countries is currently being applied in the whole world while cultural differences may imply that some countries would benefit from more local research on simulation in prehospital care. As the prehospital conditions and educations vary across different continents, there may be a need for research on simulation with other professions of prehospital care providers. The most frequently occurring research participants in this review were paramedics. However, given that EMTs are also common staff category in prehospital healthcare, simulation research with a specific focus on EMTs may need to increase. What is completely lacking in the result is the staffs' relation to the patient. This may be disregarded because there are no patients involved rather different types of simulation. Nevertheless, it might be of 
interest to elevate the patient in this context as all caregiving is for the patient.

The area which was the focus of most published articles on simulation was intubation, while ventilation was most infrequently the focus. Ventilation is a necessity for patient survival and it is important that, regardless of scenario or injury, the staff is able to manage to uphold free air passage and to ensure the supply of oxygen. World Health Organization (WHO) similarly highlights the importance of training in assisted ventilation using different types of ventilation devices (pocket mask, bag-valve-mask etc.) for both adults and infants [1]. But the knowledge on behalf of staff to ventilate adults and children was across the studies described as inadequate. This resulted for example in a performance deficiency of $25-86 \%$ for infant ventilation. Also the lack of skills in paediatric resuscitation was revealed in our study. Infants were seldom encountered in the studies which resulted in a gap of knowledge. This indicates a strong need for education and training in the prehospital care of infants.

Furthermore, survival outcome for burns victims diminished due to a lack of knowledge in estimating burned surface area. Burns victims were also seldom encountered in the studies and the staff had therefor inadequate knowledge in assessment and treating burn victims. WHO highlight the need to be able to assess degree of burns in context of depth and extent and the treat the burn victim, which they mean is essential for, advanced prehospital care providers to know [1]. Therefore, a shift of simulation research focus towards also integrating ventilation, paediatric resuscitation and management of burns victims may be beneficial. Reliable and easily accomplished techniques focusing on infants as well as burns could preferably be taught by means of simulation techniques. Subsequently, these techniques need to be followed-up and maintained to ensure adequate quality of care and patient safety. Simulation has a vital role to play in this follow-up.

With regards to CPR, in our review, poor CPR implementation during simulation identified staff not being able to accomplish CPR that would have been of clinical benefit for the actual patient. Ventilation and compressions had high percentage of incorrect performance on both adults and children. When giving CPR, it was revealed that $50 \%-90 \%$ of the ventilations, and $32-62 \%$ of the compressions were incorrectly performed. Bobrow [180] points to the gap between the perceived performance of CPR and the CPR that is actually performed. Already in 1999, Liberman emphasised the benefit and importance of staff receiving feedback on how they perform CPR [129]. Such verification, with a range of simulation scenarios, could be repeated with varying degrees of difficulty to accommodate each participant's pace of learning [4,5]. Simulation is important in building, improving and maintaining necessary skills among prehospital care providers [181], and there is an existing confirmed need for this [182]. However, Sanddal [172] notes that research needs to examine whether staged scenarios indeed are comparable to real events, something that lacks in evidence today. Future research will be particularly meaningful if the shortcomings that have been discovered by means of simulation are followed up with studies targeting on training and interventions. There is a lack of research within this area today.

The present review has highlighted published research within prehospital simulation research, an overview that might be valuable for decision regarding the direction of future research. It is important to continually build wellfounded research based knowledge about how simulation can be utilised to further staff skills and knowledge, in order to better manage the relatively rare situations when high energy trauma occurs in real-life. Future papers are needed and can do more justice to the subareas discovered in this overall review.

\section{Limitations}

The search was limited to years 1984- 2013. No countries or continents were excluded. The research participants were divided in groups where paramedics and nurses represent separate groups, given that this study adhered to description of the staff in each individual article. One limitation is that studies not indexed with the word simulation were not included. This means that studies that may have been of interest were not identified. Another limitation is that the included studies were not conducted on homogenous conditions as different cultures have varying conditions for prehospital healthcare and healthcare education. Yet another limitation is that the included articles were not subjected to a quality review, due to the primary purpose being to map the overall the research area. Whether quality should be assessed or not is, according to Whittermore and Knafl [13], controversial, as quality can often be confirmed but it is difficult to define or measure. Quality is assessed according to the information presented in the studies, which can incorrectly be interpreted as being of high or low quality depending on the manner in which it is reported [14]. In order to ensure validity in the present study, the method has been carefully described in order to enable reproduction of this study. Further, only peer-reviewed articles have been used [15].

\section{Conclusion}

Simulation is described as a positive training and education method for prehospital medical staff. It provides opportunities to train assessment, treatment and implementation of procedures and devices under realistic conditions. It is crucial that the staff has familiarity with and is well-trained for techniques in; intubation, trauma care, CPR, ventilation and triage, which all, to a very large degree, constitute 
prehospital care. Simulation plays an integral role in ensuring these skills and this level of comfort.

Previous research, as well as this review, indicates that the current state of prehospital care is inadequate in many aspects, e.g. insufficient skills for ventilation and CPR, on both children and adults, as well as paediatric resuscitation and assessment and care management of burns victims. This suggests critical areas where future simulation training and simulation research may be directed, both on a local and global level.

\section{Competing interests}

The authors declare that they have no competing interests.

\section{Authors' contributions}

AA conducted the literature search, analysed the material and wrote the manuscript. IR, BOS and LL supervised the literature search, were the additional. assessors and supervised the analysis of the material and the writing of the manuscript. All authors read and approved the final manuscript.

\section{Acknowledgements}

The authors would like to thank librarian Annelie Ekberg-Andersson for her help in conducting this literature review.

\section{Author details}

'Department of Health Sciences, Karlstad University, Karlstad, Sweden

${ }^{2}$ School of Health Science, University of Borås, Borås, Sweden.

Received: 12 October 2013 Accepted: 24 March 2014

Published: 28 March 2014

\section{References}

1. Sasser S, Varghese M, Kellermann A, Lormand JD: Prehospital trauma care systems. Geneva: World Health Organization; 2005. Assessed 20140408 http://whqlibdoc.who.int/publications/2005/924159294x.pdf.

2. Marson A, Thomson J: The influence of prehospital trauma care on traffic accident mortality. J Trauma 2001, 50:917-920.

3. Bradley P: The history of simulation in medical education and possible future directions. Med Educ 2006, 40:254-262.

4. Issenberg B, McGaghie W, Petrusa E, Gordon D, Scalese R: Features and uses of high-fidelity medical simulations that lead to effective learning: a BEME systematic review. Med Teach 2005, 27(1):10-28.

5. Maran NJ, Glavin RJ: Low- to high-fidelity simulation - a continuum of medical education? Med Educ 2003, 37(Suppl. 1):22-28.

6. Good ML: Patient simulation for training basic and advanced clinical skills. Med Educ 2003, 37(Suppl. 1):14-21.

7. Lammers R, Davenport M, Korley F, Griswold-Theodorson S, Fitch MT, Narang AT, Evans LV, Gross A, Rodriguez E, Dodge KL, Hamann C, Robey WC: Teaching and assessing procedural skills using simulation: metrics and methodology. Acad Emerg Med 2008, 15:1079-1087.

8. Criss E: Patient simulators: changing the face of ems education. JEMS 2001, 26(12):24-31.

9. Ilgen JS, Sherbino J, Cook DA: Technology-enhanced simulation in emergency medicine: a systematic review and meta-analysis. Acad Emerg Med 2013, 20(2):117-127.

10. Chakravarthy B, Ter Haar E, Bhat SS, McCoy CE, Denmark TK, Lotfipour S: Simulation in medical school education: review for emergency medicine. West J Emerg Med 2011, 12(4):461-466.

11. Sandelowski M, Voils $\mathrm{Cl}$, Barroso J: Defining and designing mixed research synthesis studies. Res Sch 2006, 13(1):29.

12. Sandelowski M, Voils C, Barroso J: Comparability work and the management of difference in research synthesis studies. Soc Sci Med 2007. 64(1):236-247.

13. Whittermore R, Knafl $K$ : The integrative review: updated methodology. JAN 2005, 52(2):546-553.

14. Jadad A, Moher D, Klassen T: Guides for reading and interpreting systematic reviews. Il. How did the authors find the studies and assess their quality? Arch Pediatr Adolesc Med 1989, 152(aug):812-817.
15. Oxman AD: Systematic reviews: checklists for review articles. Br Med J 1994, 309:648-651.

16. Aziz M, Dillman D, Kirsch JR, Brambrink A: Video laryngoscopy with the macintosh video laryngoscope in simulated prehospital scenarios by paramedic students. Prehosp Emerg Care 2009, 13(2):251-255.

17. Barnes DR, Reed DB, Weinstein G, Brown LH: Blind tracheal intubation by paramedics through the LMA-unique. Prehosp Emerg Care 2003, 7(4):470-473.

18. Boedeker BH, Berg BW, Bernhagen MA, Murray WB: Endotracheal intubationation comparing a prototype storz $\mathrm{cmac}$ and a glidescope videolaryngoscope in a medical transport helicopter - a pilot study. Stud Health Technol Inform 2009, 142:37-39.

19. Boedeker BH, Berg BW, Bernhagen M, Murray WB: Endotracheal intubation in a medical transport helicopter - comparing direct laryngoscopy with the prototype storz cmac videolaryngoscope in a simulated difficult intubating position. Stud Health Technol Inform 2009, 142:40-42.

20. Butchart AG, Tjen C, Garg A, Young P: Paramedic laryngoscopy in the simulated difficult airway: comparison of the Venner A.P. advance and glidescope ranger video laryngoscopes. Acad Emerg Med 2011, 18(7):692-698.

21. Byars DV, Brodsky RA, Evans D, Lo B, Guins T, Perkins AM: Comparison of direct laryngoscopy to pediatric king LT-D in simulated airways. Pediatr Emerg Care 2012, 28(8):750-752.

22. Castle N, Owen R, Hann M, Naidoo R, Reeves D: Assessment of the speed and ease of insertion of three supraglottic airway devices by paramedics: a manikin study. Emerg Med J 2010, 27(11):860-863.

23. Chen L, Hsiao AL: Randomized trial of endotracheal tube versus laryngeal mask airway in simulated prehospital pediatric arrest. Pediatrics 2008, 122(2):294-297.

24. Cinar O, Cevik E, Yildirim AO, Yasar M, Kilic E, Comert B: Comparison of glidescope video laryngoscope and intubationating laryngeal mask airway with direct laryngoscopy for endotracheal intubationation. Eur $J$ Emerg Med 2011, 18(2):117-120.

25. Frascone RJ, Pippert G, Heegaard W, Molinari P, Dries D: Successful training of hems personnel in laryngeal mask airway and intubating laryngeal mask airway placement. Air Med J 2008, 27(4):185-187.

26. Gregory P, Woollard M, Lighton D, Munro G, Jenkinson E, Newcombe RG, O'Meara P, Hamilton L: Comparison of malleable stylet and reusable and disposable bougies by paramedics in a simulated difficult intubation. Anaesthesia 2012, 67(4):371-376.

27. Grosomanidis V, Amaniti E, Pourzitak CH, Fyntanidou V, Mouratidis K, Vasilakos D: Comparison between intubation through ILMA and Airtraq, in different non-conventional patient positions: a manikin study. Emerg Med J 2012, 29(1):32-36.

28. Guyette FX, Roth KR, LaCovey DC, Rittenberger JC: Feasibility of laryngeal mask airway use by prehospital personnel in simulated pediatric respiratory arrest. Prehosp Emerg Care 2007, 11(2):245-249.

29. Hoyle JD Jr, Jones JS, Deibel M, Lock DT, Reischman D: Comparative study of airway management techniques with restricted access to patient airway. Prehosp Emerg Care 2007, 11(3):330-336.

30. Jokela J, Nurmi J, Genzwuerker HV, Castrén M: Laryngeal tube and intubation laryngeal mask insertion in a manikin by first-responder trainees after a short video-clip demonstration. Prehosp Disaster Med 2009, 24(1):63-66.

31. Larsen MJ, Guyette FX, Suyama J: Comparison of three airway management techniques in a simulated tactical setting. Prehosp Emerg Care 2010, 14(4):510-514

32. Le DH, Reed DB, Weinstein G, Gregory M, Brown LH: Paramedic use of endotracheal tube introducers for the difficult airway. Prehosp Emerg Care 2001, 5(2):155-158.

33. Lewis AR, Hodzovic I, Whelan J, Wilkes AR, Bowler I, Whitfield R: A paramedic study comparing the use of the Airtraq, airway scope and Macintosh laryngoscopes in simulated prehospital airway scenarios. Anaesthesia 2010, 65(12):1187-1193.

34. Menzies $\mathrm{R}$, Manji $\mathrm{H}$ : The intubating laryngeal mask: is there a role for paramedics? Emerg Med J 2007, 24(3):198-199.

35. Messa MJ, Kupas DF, Dunham DL: Comparison of bougie-assisted intubation with traditional endotracheal intubation in a simulated difficult airway. Prehosp Emerg Care 2011, 15(1):30-33.

36. Mitchell MS, Lee White M, King WD, Wang HE: Paramedic King Laryngeal tube airway insertion versus endotracheal intubation in simulated pediatric respiratory arrest. Prehosp Emerg Care 2012, 16(2):284-288. 
37. Mitterlechner T, Wipp A, Herff H, Wenzel V, Strasak AM, Felbinger TW, Schmittinger CA: A comparison of the suction laryngoscope and the Macintosh laryngoscope in emergency medical technicians: a manikin model of severe airway haemorrhage. Emerg Med J 2012, 29(1):54-55.

38. Nasim S, Maharaj CH, Butt I, Malik MA, O' Donnell J, Higgins BD, Harte BH, Laffey J: Comparison of the Airtraq and Truview laryngoscopes to the Macintosh laryngoscope for use by Advanced Paramedics in easy and simulated difficult intubation in manikins. BMC Emerg Med 2009, 13(9):2.

39. Nasim S, Maharaj CH, Malik MA, O' Donnell J, Higgins BD, Laffey JG: Comparison of the Glidescope and Pentax AWS laryngoscopes to the Macintosh laryngoscope for use by advanced paramedics in easy and simulated difficult intubation. BMC Emerg Med 2009, 17(9):9.

40. Nowicki TA, Suozzi JC, Dziedzic M, Kamin R, Donahue S, Robinson K: Comparison of use of the Airtraq with direct laryngoscopy by paramedics in the simulated airway. Prehosp Emerg Care 2009, 13(1):75-80.

41. Phelan MP, Moscati R, D'Aprix T, Miller G: Paramedic use of the endotracheal tube introducer in a difficult airway model. Prehosp Emerg Care 2003, 7(2):244-246.

42. Piepho T, Weinert K, Heid FM, Werner C, Noppens RR: Comparison of the McGrath ${ }^{\circledast}$ Series 5 and GlideScope ${ }^{\circledast}$ Ranger with the Macintosh laryngoscope by paramedics. Scand J Trauma Resusc Emerg Med 2011, 19(1):4.

43. Polk JD, Super DM, Kovach B, Russell S, Mancuso C, Fallon W: Comparison of the laryngeal mask airway versus blind endotracheal intubation in the simulated entrapped patient: a preliminary study. Air Med J 2001, 20(2):21-22.

44. Ritter SC, Guyette FX: Prehospital pediatric King LT-D use: a pilot study. Prehosp Emerg Care 2011, 15(3):401-404.

45. Rumball C, Macdonald D, Barber P, Wong H, Smecher C: Endotracheal intubation and esophageal tracheal Combitube insertion by regular ambulance attendants: a comparative trial. Prehosp Emerg Care 2004, 8(1):15-22.

46. Russi CS, Wilcox CL, House HR: The laryngeal tube device: a simple and timely adjunct to airway management. Am J Emerg Med 2007, 25(3):263-267.

47. Russi CS, Miller L, Hartley MJ: A comparison of the King-LT to endotracheal intubation and Combitube in a simulated difficult airway. Prehosp Emerg Care 2008, 12(1):35-41.

48. Ruetzler K, Roessler B, Potura L, Priemayr A, Robak O, Schuster E, Frass M: Performance and skill retention of intubation by paramedics using seven different airway devices -a manikin study. Resuscitation 2011, 82(5):593-597.

49. Swanson ER, Fosnocht DE, Matthews K, Barton ED: Comparison of the intubation laryngeal mask airway versus laryngoscopy in the Bell 206-L3 EMS helicopter. Air Med J 2004, 23(1):36-39.

50. Varney SM, Dooley M, Bebarta VS: Faster intubation with direct laryngoscopy vs handheld videoscope in uncomplicated manikin airways. Am J Emerg Med 2009, 27(3):259-261.

51. Woollard M, Lighton D, Mannion W, Watt J, McCrea C, Johns I, Hamilton L, O'Meara P, Cotton C, Smyth M: Airtraq vs standard laryngoscopy by student paramedics and experienced prehospital laryngoscopists managing a model of difficult intubation. Anaesthesia 2008, 63(1):26-31.

52. Givens GC, Shelton SL, Brown EA: Emergency cricothyrotomy in confined space airway emergencies: a comparison. Prehosp Emerg Care 2011, 26(04):259-261.

53. Woollard M, Mannion W, Lighton D, Johns I, O'meara P, Cotton C, Smyth M: Use of the Airtraq laryngoscope in a model of difficult intubation by prehospital providers not previously trained in laryngoscopy. Anaesthesia 2007, 62(10):1061-1065.

54. Davis DP, Buono C, Ford J, Paulson L, Koenig W, Carrison D: The effectiveness of a novel, algorithm-based difficult airway curriculum for air medical crews using human patient simulators. Prehosp Emerg Care 2007, 11(1):72-79.

55. Batchelder AJ, Steel A, Mackenzie R, Hormis AP, Daniels TS, Holding N: Simulation as a tool to improve the safety of pre-hospital anaesthesia-a pilot study. Anaesthesia 2009, 64(9):978-983.

56. Bradley JS, Billows GL, Olinger ML, Boha SP, Cordell WH, Nelson DR: Prehospital oral endotracheal intubation by rural basic emergency medical technicians. Ann Emerg Med 1998, 32(1):26-32

57. Guyette FX, Rittenberger JC, Platt T, Suffoletto B, Hostler D, Wang HE: Feasibility of basic emergency medical technicians to perform selected advanced life support interventions. Prehosp Emerg Care 2006, 10(4):518-521.

58. Hein C, Owen H, Plummer J: A training program for novice paramedics provides initial laryngeal mask airway insertion skill and improves skill retention. Simul Healthc 2010, 5(1):33-39.
59. Kelmenson C, Salzman J, Griffith K, Kaye K, Frascone RJ: Focus on RSI: Does training in the or create an optimal RSI program? JEMS 2008, 33(3):110-112.

60. March JA, Farrow JL, Brown LH, Dunn KA, Perkins PK: A breathing manikin model for teaching nasotracheal intubation to EMS professionals. Prehosp Emerg Care 1997, 1(4):269-272.

61. Murray MJ, Vermeulen MJ, Morrison LJ, Waite T: Evaluation of prehospital insertion of the laryngeal mask airway by primary care paramedics with only classroom mannequin training. CJEM 2002, 4(5):338-343.

62. Sayre MR, Sakles J, Mistler A, Evans J, Kramer A, Pancioli AM: Teaching basic EMTs endotracheal intubation: can basic EMTs discriminate between endotracheal and esophageal intubation? Prehosp Disaster Med 1994, 9(4):234-237.

63. Youngquist ST, Henderson DP, Gausche-Hill M, Goodrich SM, Poore PD, Lewis RJ: Paramedic self-efficacy and skill retention in pediatric airway management. Acad Emerg Med 2008, 15(12):1295-1303.

64. Hall RE, Plant JR, Bands CJ, Wall AR, Kang J, Hall CA: Human patient simulation is effective for teaching paramedic students endotracheal intubation. Acad Emerg Med 2005, 12(9):850-855.

65. Stewart RD, Paris PM, Pelton GH, Garretson D: Effect of varied training techniques on field endotracheal intubation success rates. Ann Emerg Med 1984, 13(11):1032-1036.

66. Trooskin SZ, Rabinowitz S, Eldridge C, McGowan DE, Flancbaum L: Teaching endotracheal intubation using animals and cadavers. Prehosp Disaster Med 1992, 7(02):179-182.

67. Adnet F, Lapostolle F, Borron SW, Hennequin B, Leclercq G, Fleury M: Optimization of glottic exposure during intubation of a patient lying supine on the ground. Am J Emerg Med 1997, 15(6):555-557.

68. Robinson K, Donaghy K, Katz R: Inverse intubation in air medical transport. Air Med J 2004, 23(1):40-43.

69. Thomas SH, Farkas A, Wedel S: Cabin configuration and prolonged oral endotracheal Intubationation in the AS365N2 Dauphin EMS helicopter. Air Med J 1996, 15(2):65-68

70. Castle N, Pillay Y, Spencer N: What is the optimal position of an intubator wearing CBRN-PPE when intubating on the floor: a manikin study. Resuscitation 2011, 82(5):588-592.

71. Pinchalk M, Roth RN, Paris PM, Hostler D: Comparison of times to intubate a simulated trauma patient in two positions. Prehosp Emerg Care 2003, 7(2):252-257.

72. Samuel N, Winkler K, Peled S, Krauss B, Shavit I: External laryngeal manipulation does not improve the intubation success rate by novice intubators in a manikin study. Am J Emerg Med 2012, 30(9):2005-2010.

73. Parwani V, Hoffman RJ, Russell A, Bharel C, Preblick C, Hahn $\|$ : Practicing paramedics cannot generate or estimate safe endotracheal tube cuff pressure using standard techniques. Prehosp Emerg Care 2007, 11(3):307-311.

74. Castle N, Owen R, Clark S, Hann M, Reeces D, Gurney I: Comparison of techniques for securing the endotracheal tube while wearing chemical, biological, radiological, or nuclear protection: a manikin study. Prehosp Disaster Med 2010, 25(6):589-594.

75. Gough JE, Thomas SH, Brown LH, Reese JE, Stone CK: Does the ambulance environment adversely affect the ability to perform oral endotracheal intubation? Prehosp Disaster Med 1996, 11(2):141-143.

76. Kim YM, Kang HG, Kim JH, Chung HS, Yim HW, Jeong SH: Direct versus video laryngoscopic intubation by novice prehospital intubators with and without chest compressions: a pilot manikin study. Prehosp Emerg Care 2011, 15(1):98-103.

77. Bond WF, Kostenbader M, McCarthy JF: Prehospital and hospital-based health care providers' experienced with a human patient simulator. Prehosp Emerg Care 2001, 5(3):284-287.

78. Hinchey PR, De Maio VJ, Patel A, Cabañas JG: Air medical providers' physiological response to a simulated trauma scenario. Air Med J 2011, 30(2):86-90

79. Wyatt $A$, Archer F, Fallows B: Use of simulators in teaching and learning paramedics' evaluation of a patient simulator? JEPHC 2007, 5(2):1-16.

80. Barsuk D, Berkenstadt H, Stein M, Lin G, Ziv A: Advanced patient simulators in pre-hospital trauma management training - the trainees' perspective. Harefuah 2003, 142(2):87-90.

81. Kim TE, Reibling ET, Denmark KT: Student perception of high fidelity medical simulation for an international trauma life support course. Prehosp Disaster Med 2012, 27(1):27-30. 
82. Willett TG, Kirlew M, Cardinal P, Karas P: An evaluation of the Acute Critical Events Simulation (ACES) course for family medicine residents. Can $J$ Rural Med 2011, 16(3):89-95.

83. Gillett B, Peckler B, Sinert R, Onkst C, Nabors S, Issley S, Maguire C, Galwankarm S, Arquilla B: Simulation in a disaster drill: comparison of high-fidelity simulators versus trained actors. Acad Emerg Med 2008, 15(11):1144-1151.

84. Sergeev I, Lipsky AM, Ganor O, Lending G, Abebe-Campino G, Morose A, Katzenell U, Ash N, Glassberg E: Training modalities and self-confidence building in performance of life-saving procedures. Mil Med 2012, 177(8):901-906.

85. Lammers R, Byrwa M, Fales W: Root causes of errors in a simulated prehospital pediatric emergency. Acad Emerg Med 2012, 19(1):37-47.

86. Treloar D, Hawayek J, Montgomery JR, Russell W: On-site and distance education of emergency medicine personnel with a human patient simulator. Mil Med 2001, 166(11):1003-1006.

87. Hemman EA: Improving combat medic learning using a personal computer-based virtual training simulator. Mil Med 2005, 170(9):723-727.

88. Wilkerson W, Avstreih D, Gruppen L, Beier KP, Woolliscroft J: Using immersive simulation for training first responders for mass casualty incidents. Acad Emerg Med 2008, 15(11):1152-1159.

89. Williams B, Brown T, Archer F: Can dvd simulations provide an effective alternative for paramedic clinical placement education? Emerg Med J 2009, 26(5):377-381.

90. Williams B, Brown T, Scholes R, French J, Archer F: Can interdisciplinary clinical DVD simulations transform clinical fieldwork education for paramedic, occupational therapy, physiotherapy, and nursing students? J Allied Health 2010, 39(1):3-10.

91. Spaite DW, Karriker KJ, Seng M, Conroy C, Battaglia N, Tibbitts M, Salik RM: Training paramedics: emergency care for children with special health care needs. Prehosp Emerg Care 2000, 4(2):178-185.

92. Studnek JR, Fernandez AR, Shimberg B, Garifo M, Correll M: The association between emergency medical services field performance assessed by high-fidelity simulation and the cognitive knowledge of practicing paramedics. Acad Emerg Med 2011, 18(11):1177-1185.

93. Leblanc VR, Regehr C, Tavares W, Scott AK, Macdonald R, King K: The impact of stress on paramedic performance during simulated critical events. Prehosp Disaster Med 2012, 27(4):369-374.

94. Wright SW, Lindsell CJ, Hinckley WR, Williams A, Holland C, Lewis CH, Heimburger G: High fidelity medical simulation in the difficult environment of a helicopter: feasibility, self-efficacy and cost. BMC Med Educ 2006, 5(6):49.

95. Rubiano AM, Sánchez Al, Guyette F, Puyana JC: Trauma care training for national police nurses in Colombia. Prehosp Emerg Care 2010, 14(1):124-130

96. Miller GT, Scott JA, Issenberg SB, Petrusa ER, Brotons AA, Gordon DL, McGaghie WC, Gordon MS: Development, implementation and outcomes of a training program for responders to acts of terrorism. Prehosp Emerg Care 2006, 10(2):239-246

97. Scott JA, Miller GT, Issenberg SB, Brotons AA, Gordon DL, Gordon MS, McGaghie WC, Petrusa ER: Skill improvement during emergency response to terrorism training. Prehosp Emerg Care 2006, 10(4):507-514.

98. Kobayashi L, Suner S, Shapiro MJ, Jay G, Sullivan F, Overly F, Seekell C, Hill A, Williams KA: Multipatient disaster scenario design using mixed modality medical simulation for the evaluation of civilian prehospital medical response: a "dirty bomb" case study. Simul Healthc 2006, 1(2):72-78.

99. Klein KR, Atas JG, Collins J: Testing emergency medical personnel response to patients with suspected infectious disease. Prehosp Disaster Med 2004, 19(3):256-265.

100. Subbarao I, Bond WF, Johnson C, Hsu EB, Wasser TE: Using innovative simulation modalities for civilian-based, chemical, biological, radiological, nuclear, and explosive training in the acute management of terrorist victims: A pilot study. Prehosp Disaster Med 2006, 21(4):272-275.

101. Lammers RL, Byrwa MJ, Fales WD, Hale RA: Simulation-based assessment of paramedic pediatric resuscitation skills. Prehosp Emerg Care 2009, 13(3):345-356.

102. Anderson TE, Arthur K, Kleinman M, Drawbaugh R, Eitel DR, Ogden CS, Baker D: Intraosseous infusion: success of a standardized regional training program for prehospital advanced life support providers. Ann Emerg Med 1994, 23(1):52-55.

103. Miller DD, Guimond G, Hostler DP, Platt T, Wang HE: Feasibility of sternal intraosseous access by emergency medical technician students. Prehosp Emerg Care 2005, 9(1):73-78.
104. Findlay J, Johnson DL, Macnab AJ, MacDonald D, Shellborn R, Susak L: Paramedic evaluation of adult intraosseous infusion system. Prehosp Disaster Med 2006, 21(5):329-334.

105. McDermott C, Collins NC: Prehospital medication administration: a randomised study comparing intranasal and intravenous routes. Emerg Med Int 2012. doi:10.1155/2012/476161.

106. Brooke M, Walton J, Scutt D, Connolly J, Jarman B: Acquisition and interpretation of focused diagnostic ultrasound images by ultrasound-naive advanced paramedics: trialling a PHUS education programme. Emerg Med J 2012, 29(4):322-326.

107. Heiner JD, McArthur TJ: The ultrasound identification of simulated long bone fractures by prehospital providers. Wilderness Environ Med 2010, 21(2):137-140.

108. Charash WE, Caputo MP, Clark H, Callas PW, Rogers FB, Crookes BA, Alborg MS, Ricci MA: Telemedicine to a moving ambulance improves outcome after trauma in simulated patients. J Trauma 2011, 71(1):49-54

109. Skorning M, Bergrath S, Rörtgen D, Beckers SK, Brokmann JC, Gillmann B, Herding J, Protogerakis M, Fitzner C, Rossaint R: Teleconsultation in prehospital emergency medical services: real-time telemedical support in a prospective controlled simulation study. Resuscitation 2012, 83(5):626-632

110. Rissanen S, Jousela I, Jeong JR, Rintamäki H: Heat stress and bulkiness of chemical protective clothing impair performance of medical personnel in basic lifesaving tasks. Ergonomics 2008, 51(7):1011-1022

111. Schumacher J, Gray SA, Weidelt L, Brinker A, Prior K, Stratling WM: Comparison of powered and conventional air-purifying respirators during simulated resuscitation of casualties contaminated with hazardous substances. Emerg Med J 2009, 26(7):501-505.

112. Brummer S, Dickinson ET, Shofer FS, McCans JP, Mechem CC: Effect of night vision goggles on performance of advanced life support skills by emergency personnel. Mil Med 2006, 171(4):280-282.

113. Henriksson O, Lundgren $P$, Kuklane $K$, Holmér I, Naredi $P$, Bjornstig U: Protection against cold in prehospital care: evaporative heat loss reduction by wet clothing removal or the addition of a vapor barrier - a thermal manikin study. Prehosp Disaster Med 2012, 27(1):53-58.

114. Henriksson O, Lundgren JP, Kuklane K, Holmér I, Bjornstig U: Protection against cold in prehospital care - thermal insulation properties of blankets and rescue bags in different wind conditions. Prehosp Disaster Med 2009, 24(5):408-415.

115. Skulec R, Truhlár A, Dostál P, Seblová J, Knor J, Dostálová G, Skulec S, Cerny $\checkmark$ : Prehospital cooling by cold infusion: searching for the optimal infusion regimen. Emerg Med J 2011, 28(8):695-699.

116. Campbell M, Weiss S, Froman P, Cheney P, Gadomski D, Alexander-Shook M, Ernst A: Impact of a restraint training module on paramedic students' likelihood to use restraint techniques. Prehosp Emerg Care 2008, 12(3):388-392.

117. King RB, Filips D, Blitz S, Logsetty S: Evaluation of possible tourniquet systems for use in the canadian forces. J Trauma 2006, 60(5):1061-1071.

118. Breederveld RS, Nieuwenhuis MK, Tuinebreijer WE, Aardenburg B: Effect of training in the emergency management of severe burns on the knowledge and performance of emergency care workers as measured by an online simulated burn incident. Burns 2011, 37(2):281-287.

119. Smith JJ, Malyon AD, Scerri GV, Burge TS: A comparison of serial halving and the rule of nines as a pre-hospital assessment tool in burns. $\mathrm{Br} J$ Plast Surg 2005, 58(7):957-967.

120. Sahni R, Menegazzi JJ, Mosesso VN Jr: Paramedic evaluation of clinical indicators of cervical spinal injury. Prehosp Emerg Care 1997, 1(1):16-18.

121. Frank M, Schmucker U, Stengel D, Fischer L, Lange J, Grossjohann R, Ekkernkamp A, Matthes G: Proper estimation of blood loss on scene of trauma: tool or tale? J Trauma 2010, 69(5):1191-1195.

122. Tall G, Wise D, Grove P, Wilkinson C: The accuracy of external blood loss estimation by ambulance and hospital personnel. Emerg Med (Fremantle) 2003, 15(4):318-321.

123. Williams B, Boyle M: Estimation of external blood loss by paramedics: is there any point? Prehosp Disaster Med 2007, 22(6):502-506.

124. Barnekow-Bergkvist M, Aasa U, Angquist KA, Johansson H: Prediction of development of fatigue during a simulated ambulance work task from physical performance tests. Ergonomics 2004, 47(11):1238-1250.

125. Lavender SA, Conrad KM, Reichelt PA, Johnson PW, Meyer FT: Biomechanical analyses of paramedics simulating frequently performed strenuous work tasks. Appl Ergon 2000, 31(2):167-177. 
126. Lavender SA, Conrad KM, Reichelt PA, Meyer FT, Johnson PW: Postural analysis of paramedics simulating frequently performed strenuous work tasks. Appl Ergon 2000, 31(1):45-57.

127. Sherwood HB, Donze A, Giebe J: Mechanical vibration in ambulance transport. J Obstet Gynecol Neonatal Nurs 1994, 23(6):457-463.

128. Brown TB, Dias JA, Saini D, Shah RC, Cofield SS, Terndrup TE, Kaslow RA Waterbor JW: Relationship between knowledge of cardiopulmonary resuscitation guidelines and performance. Resuscitation 2006 69(2):253-261.

129. Liberman M, Lavoie A, Mulder D, Sampalis J: Cardiopulmonary resuscitation: errors made by pre-hospital emergency medical personnel. Resuscitation 1999, 42(1):47-55.

130. Nielsen AM, Isbye DL, Lippert FK, Rasmussen LS: Basic life support and automated external defibrillator skills among ambulance personnel: a manikin study performed in a rural low-volume ambulance setting. Scand j Trauma Resusc Emerg Med 2012, 8(20):34.

131. Woollard M, Poposki J, McWhinnie B, Rawlins L, Munro G, O'Meara P: Achy breaky makey wakey heart? A randomised crossover trial of musical prompts. Emerg Med J 2012, 29(4):290-294.

132. Bayley $R$, Weinger M, Meador S, Slovis C: Impact of ambulance crew configuration on simulated cardiac arrest resuscitation. Prehosp Emerg Care 2008, 12(1):62-68

133. Braunfels S, Meinhard K, Zieher B, Koetter KP, Maleck WH, Petroianu GA: A randomized, controlled trial of the efficacy of closed chest compressions in ambulances. Prehosp Emerg Care 1997, 1(3):128-131.

134. Hüpfl M, Duma A, Uray T, Maier C, Fiegl N, Bogner N, Nagele P: Over-thehead cardiopulmonary resuscitation improves efficacy in basic life support performed by professional medical personnel with a single rescuer: a simulation study. Anesth Analg 2005, 101(1):200-205.

135. Kim JA, Vogel D, Guimond G, Hostler D, Wang HE, Menegazzi JJ: A randomized, controlled comparison of cardiopulmonary resuscitation performed on the floor and on a moving ambulance stretcher. Prehosp Emerg Care 2006, 10(1):68-70

136. Ilper H, Kunz T, Pfleger H, Schalk R, Byhahn C, Ackermann H, Breitkreutz R: Comparative quality analysis of hands-off time in simulated basic and advanced life support following european resuscitation council 2000 and 2005 guidelines. Emerg Med J 2012, 29(2):95-99.

137. Wik L, Steen PA: The ventilation/compression ratio influences the effectiveness of two rescuer advanced cardiac life support on a manikin. Resuscitation 1996, 31(2):113-119.

138. Martin-Gill C, Guyette FX, Rittenberger JC: Effect of crew size on objective measures of resuscitation for out-of-hospital cardiac arrest. Prehosp Emerg Care 2010, 14(2):229-234

139. Bollig G, Steen PA, Wik L: Standard versus over-the-head cardiopulmonary resuscitation during simulated advanced life support. Prehosp Emerg Care 2007, 11(4):443-447.

140. Kim CH, Kim GW: The efficacy of alternative cardiopulmomonary resuscitation methods when compared to standard cardiopulmonary resuscitation: a simulation study. Hong Kong J Emerg Med 2012, 19(4):242-248.

141. Maisch S, Gamon E, llisch A, Goetz AE, Schmidt GN: Comparison of the over-the-head, lateral and alternating positions during cardiopulmonary resuscitation performed by a single rescuer with a bag-valve-mask device. Emerg Med J 2011, 28(11):974-978.

142. Claesson A, Karlsson T, Thorén AB, Herlitz J: Delay and performance of cardiopulmonary resuscitation in surf lifeguards after simulated cardiac arrest due to drowning. Am J Emerg Med 2011, 29(9):1044-1050.

143. Chung TN, Kim SW, Cho YS, Chung SP, Park I, Kim SH: Effect of vehicle speed on the quality of closed-chest compression during ambulance transport. Resuscitation 2010, 81(7):841-847.

144. Stone CK, Thomas SH: Can correct closed-chest compressions be performed during prehospital transport? Prehosp Disaster Med 1995, 10(2):121-123.

145. Hostler D, Wang H, Parrish K, Platt TE, Guimond G: The effect of a voice assist manikin (VAM) system on CPR quality among prehospital providers. Prehosp Emerg Care 2005, 9(1):53-60.

146. Watson L, Sault W, Gwyn R, Verbeek PR: The "delay effect" of donning a gown during cardiopulmonary resuscitation in a simulation model. CJEM 2008, 10(4):333-338

147. MacDonald RD, LeBlanc V, McArthur B, Dubrowski A: Performance of resuscitation skills by paramedic personnel in chemical protective suits. Prehosp Emerg Care 2006, 10(2):254-259.
148. Aune S, Karlsson T, Herlitz J: Evaluation of 2 different instruments for exposing the chest in conjunction with a cardiac arrest. Am J Emerg Med 2011, 29(5):549-553.

149. Blomberg H, Gedeborg R, Berglund L, Karlsten R, Johansson J: Poor chest compression quality with mechanical compressions in simulated cardiopulmonary resuscitation: a randomized, cross-over manikin study. Resuscitation 2011, 82(10):1332-1337.

150. Sunde K, Wik L, Steen PA: Quality of mechanical, manual standard and active compression-decompression cpr on the arrest site and during transport in a manikin model. Resuscitation 1997, 34(3):235-242.

151. Skogvoll E, Wik L: Active compression-decompression cardiopulmonary resuscitation (ACD-CPR) compared with standard CPR in a manikin model-decompression force, compression rate, depth and duration. Resuscitation 1997, 34(1):11-16.

152. Chi CH, Wu FG, Wu TH: Rescuers' effect on active compressiondecompression cardiopulmonary resuscitation (ACD-CPR) operating. Am J Emerg Med 2003, 21(7):561-562.

153. Tomte O, Sunde K, Lorem T, Auestad B, Souders C, Jensen J, Wik L: Advanced life support performance with manual and mechanical chest compressions in a randomized, multicentre manikin study. Resuscitation 2009, 80(10):1152-1157.

154. Segal N, Laurent F, Maman L, Plaisance P, Augustin P: Accuracy of a feedback device for cardiopulmonary resuscitation on a dental chair. Emerg Med J 2012, 29(11):890-893.

155. Thomas SH, Stone CK, Austin PE, March JA, Brinkley S: Utilization of a pressure-sensing monitor to improve in-flight chest compressions. Am J Emerg Med 1995, 13(2):155-157.

156. Adams BD, Carr B, Raez A, Hunter CJ: Cardiopulmonary resuscitation in the combat hospital and forward operating base: use of automated external defibrillators. Mil Med 2009, 174(6):584-587.

157. Pytte M, Pedersen TE, Ottem J, Rokvam AS, Sunde K: Comparison of hands-off time during CPR with manual and semi-automatic defibrillation in a manikin model. Resuscitation 2007, 73(1):131-136.

158. Hoadley TA: Learning advanced cardiac life support: a comparison study of the effects of low- and high-fidelity simulation. Nurs Educ Perspect 2009, 30(2):91-95.

159. Siebers C, Müssig B, Huppertz T, Kanz KG: Atemwegsmanagement in der initialphase der reanimation = airway management in the initial phase of resuscitation. Notfall \& Rettungsmedizin 2009, 12(4):277-282.

160. Greeslade GL: Single operator cardiopulmonary resuscitation in ambulances. Which ventilationn device? Anaesthesia 1991, 46(5):391-394

161. Ariawan I, Agustini M, Seamans Y, Tsu V, Kosim MS: Choosing the appropriate neonatal resuscitation device for village midwives. J Perinatol 2011, 31(10):664-670

162. Terndrup TE, Kanter RK, Cherry RA: A comparison of infant ventilationn methods performed by prehospital personnel. Ann Emerg Med 1989 18(6):607-611

163. Terndrup TE, Warner DA: Infant ventilation and oxygenation by basic life support providers: comparison of methods. Prehosp Disaster Med 1992, 7(1):35-40.

164. Davidovic L, LaCovey D, Pitetti RD: Comparison of 1- versus 2-person bag-valve-mask techniques for manikin ventilationn of infants and children. Ann Emerg Med 2005, 46(1):37-42.

165. Nehme Z, Boyle MJ: Smaller self-inflating bags produce greater guideline consistent ventilationn in simulated cardiopulmonary resuscitation. BMC Emerg Med 2009, 20(9):4. doi:10.1186/1471-227X-9-4.

166. Terndrup TE, Cherry RA, McCabe JB: Comparison of ventilation performance: standard resuscitation bag and the resuscitation bag controller. J Emerg Med 1990, 8(2):121-125.

167. Fluck RR Jr, Sorbello JG: Comparison of tidal volumes, minute ventilation, and respiratory frequencies delivered by paramedic and respiratory care students with pocket mask versus demand valve. Respir Care 1991, 36(10):1105-1112.

168. Simon EL, Lecat PJ, Haller NA, Williams CJ, Martin SW, Carney JA, Pakiela JA: Improved auscultation skills in paramedic students using a modified stethoscope. J Emerg Med 2012, 43(6):1091-1097.

169. Langhan ML, Ching K, Northrup V, Alletag M, Kadia P, Santucci K, Chen L: A randomized controlled trial of capnography in the correction of simulated endotracheal tube dislodgement. Acad Emerg Med 2011, 18(6):590-596.

170. Kilner T: Triage decisions of prehospital emergency health care providers, using a multiple casualty scenario paper exercise. Emerg Med J 2002, 19(4):348-353. 
171. Vincent DS, Berg BW, Ikegami K: Mass-casualty triage training for international healthcare workers in the Asia-Pacific region using manikin-based simulations. Prehosp Disaster Med 2009, 24(3):206-213

172. Sanddal TL, Loyacono T, Sanddal ND: Effect of jumpstart training on immediate and short-term pediatric triage performance. Pediatr Emerg Care 2004, 20(11):749-753.

173. Cicero MX, Auerbach MA, Zigmont J, Riera A, Ching K, Baum CR: Simulation training with structured debriefing improves residents' pediatric disaster triage performance. Prehosp Disaster Med 2012, 27(3):239-244.

174. Vincent DS, Burgess L, Berg BW, Connolly KK: Teaching mass casualty triage skills using iterative multimanikin simulations. Prehosp Disaster Med 2009, 13(2):241-246.

175. Chi CH, Chao WH, Chuang CC, Tsai MC, Tsai LM: Emergency medical technicians' disaster training by tabletop exercise. Am J Emerg Med 2001, 19(5):433-436.

176. Idrose AM, Adnan WA, Villa GF, Abdullah AH: The use of classroom training and simulation in the training of medical responders for airport disaster. Emerg Med J 2007, 24(1):7-11.

177. Landis SS, Benson NH, Whitley TW: A comparison of four methods of testing emergency medical technician triage skills. Am J Emerg Med 1989, 7(1):1-4.

178. Rehn M, Vigerust T, Andersen JE, Krüger AJ, Lossius HM: Major incident patient evacuation: full-scale field exercise feasibility study. Air Med J 2011, 30(3):153-157.

179. Lerner EB, Schwartz RB, Coule PL, Pirrallo RG: Use of salt triage in a simulated mass-casualty incident. Prehosp Emerg Care 2010, 14(1):21-25.

180. Leary M, Walsh D, Battaglia N, O'Connor R, Abella B, Bobrow B: The experts weigh in: a CPR quality improvement roundtable. In CPR Performance Counts: Quality Improves Survival. San Diego, CA: Elsevier Safety Publications; 2010:16-19.

181. Weinberg $E$, Auerbach $M$, Shah $N$ : The use of simulation for pediatric training and assessment. Curr Opin Pediatr 2009, 21:282-287.

182. Abelsson A, Lindwall L: The Prehospital assessment of severe trauma patients' performed by the specialist ambulance nurse in Sweden - a phenomenographic study. Scand J Trauma Resusc Emerg Med 2012, 20(67):1-8.

doi:10.1186/1757-7241-22-22

Cite this article as: Abelsson et al:: Mapping the use of simulation in prehospital care - a literature review. Scandinavian Journal of Trauma, Resuscitation and Emergency Medicine 2014 22:22.

\section{Submit your next manuscript to BioMed Central and take full advantage of:}

- Convenient online submission

- Thorough peer review

- No space constraints or color figure charges

- Immediate publication on acceptance

- Inclusion in PubMed, CAS, Scopus and Google Scholar

- Research which is freely available for redistribution 